Mental Health in the School System:

Providing Tools and Resources for Teachers

by

Hannah N Skinner

A Capstone Presented in Partial Fulfillment

of the Requirement for the Degree of

DOCTOR OF OCCUPATIONAL THERAPY

University of St. Augustine for Health Sciences

April, 2020 
Mental Health in the School System:

Providing Tools and Resources for Teachers

by

Hannah N Skinner

has been approved

April, 2020

APPROVED:

Kayla Collins, EdD, OTR/L, Doctoral Coordinator

Thais Petrocelli, OTD, OTR/L, Doctoral Coordinator

Mary Shotwell, PhD, OT/L, Program Director

ACCEPTED AND SIGNED:

Kayla Collins

Kayla Collins, EdD, OTR/L, Doctoral Coordinator

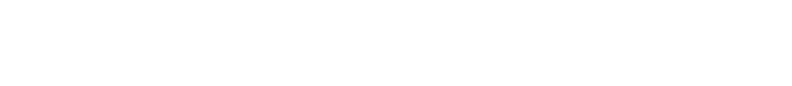

Thais Petrocelli, OTD, OTR/L, Doctoral Coordinator

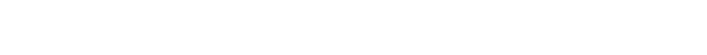

FAOTA

DN: cn=Mary P. Shotwell, $P$ PhD, OT/L, FAOTA, o=University of
St. Augustine, ou, email=mshotwell@usa.edu, $c=U S$
Date: 2020.08 .13 14:40:05-04'00

Mary Shotwell, PhD, OT/L, Program Director 
Table of Contents

Chapters

Pages:

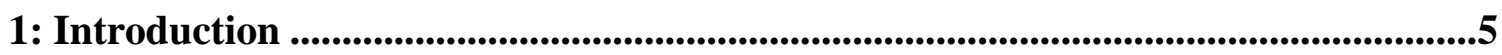

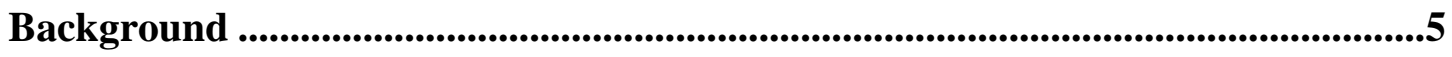

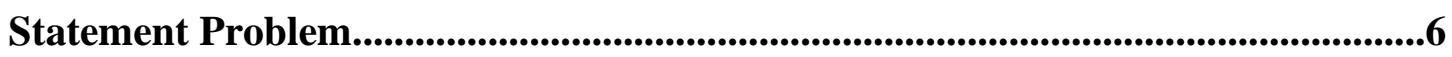

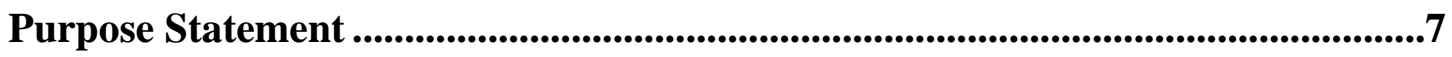

Rationale for Proposed Project....................................................................................................7

Significance of the Proposed Project ...............................................................................7

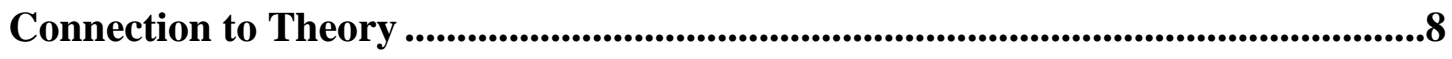

Preliminary Project Objectives ................................................................................9

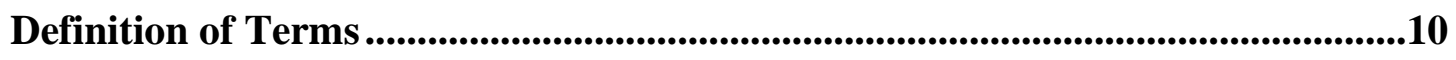

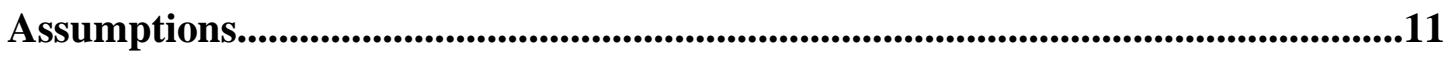

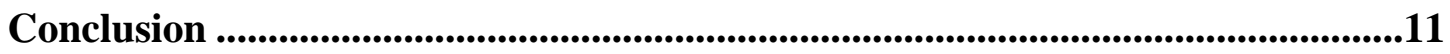

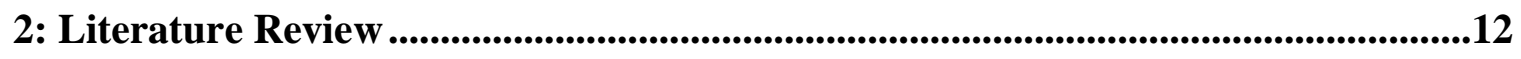

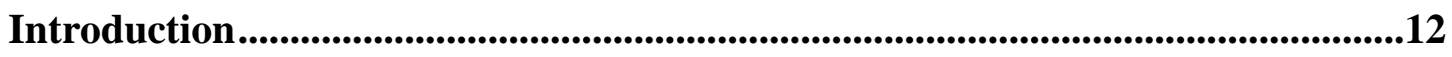

Occupational Therapy in the Schools ....................................................................12

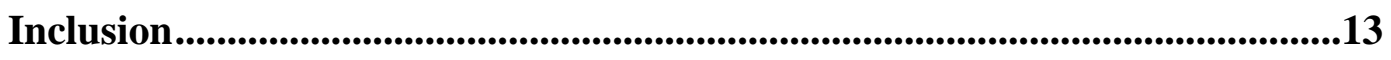

OT and Mental Health.........................................................................................13

Schools and Students ................................................................................................14

Mindfulness and Mental Wellness................................................................................15

Current Practices .......................................................................................................................16

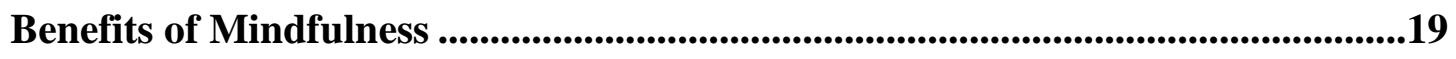

Mindfulness Changes the Brain...................................................................19 
Benefits for Students...........................................................................................................20

Benefits for Educators .......................................................................................20

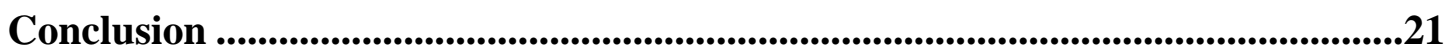

3: Project Description ....................................................................................................................21

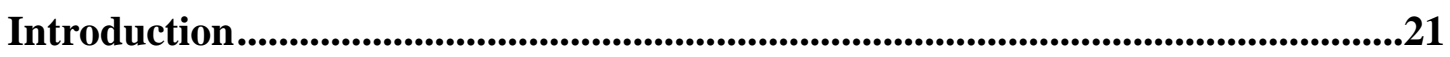

Process and Methods ..................................................................................................................23

Participants........................................................................................................................23

Setting and Measures...........................................................................................23

Development Process .............................................................................................................24

Implementation Process ........................................................................................................25

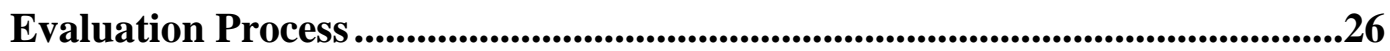

Alignment with Objectives ..................................................................................................27

Conceptual Framework ...........................................................................................................28

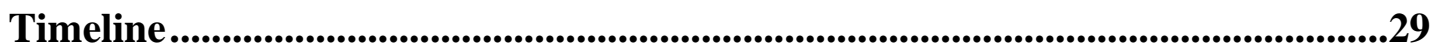

Needs Assessment ..........................................................................................................29

Implement the Developed Mindfulness Product.....................................................29

Monitor Implementation of Program Practices.........................................................30

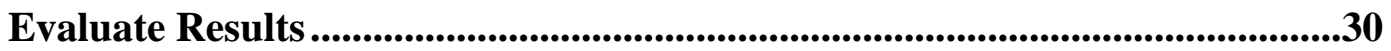

Conclusion and Next Steps ..................................................................................................30

4: Planned Analysis and Implications on Profession ..........................................................31

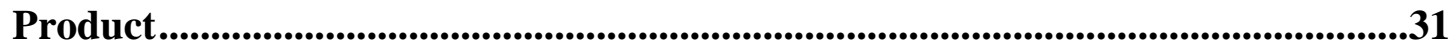

Measurement of Effectiveness ...............................................................................................33

Results and Discussion...........................................................................................................35 
Results of Project ...............................................................................................................35

Implications of Profession of Occupational Therapy ............................................35

Limitations and Delimitations ...................................................................................................36

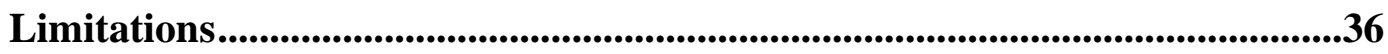

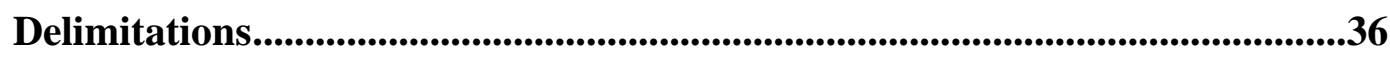

5: Summary, Conclusion, and Discussion....................................................................................37

Summary of Previous Chapters............................................................................................37

Future Considerations .............................................................................................37

Conclusion .......................................................................................................................................38

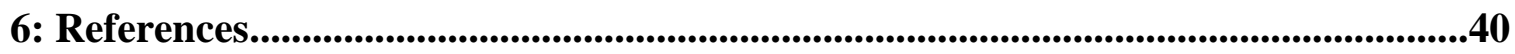




\section{Chapter I: Introduction}

\section{Background}

Mental health awareness has become a frequent topic of discussion in today's culture. However, there is often discomfort associated with addressing the mental health concerns of others. Mental health can be defined by how one handles emotions, feelings, and stress, acts towards others, and makes decisions (Mentalhealth.gov, 2017). We have seen a rise in mental health illness rates over the past 10 to 20 years in the population as a whole, but most significantly in children and adolescents, with symptoms arising around the age of 14 years old (Healthy Youth Survey, 2018; US Department of Health and Human Services [HHS], 2018). In fact, HHS (2018) states that one in five adolescents will experience a mental health disorder.

Adolescents in schools are seen to have high rates of stress, depression and anxiety (Tereda, 2017). These rates are continuing to increase. Many students are often lying awake at night, which disrupts their sleep schedule and negatively affects their academics, interactions, coping, and self-regulation (Tereda, 2017; Zenner, Herrnleben-Kurz, \& Walach, 2014). Family socioeconomic issues and trauma can also affect adolescent behaviors and mental health (Centers for Disease Control [CDC], 2019; Whiting, 2018). According to the American Psychological Association (2019), trauma can be defined as "an emotional response to a terrible event," such as natural disasters, motor vehicle accidents or other experiences of the macabre. The ability to cope with these traumas as well as other adverse experiences and factors affecting the students' mental status may be important in the student's overall health. Tereda (2018) states that the high stress rates in students can have long lasting effects as adults. Therefore, it is important to support students and to provide the tools to address stress in a healthy way. 
Due to the high ratio of children to school psychologists, mental health is not being adequately addressed in the school system, consequently allowing many children to go without needed services. Staff and teachers do not feel confident in providing mental health strategies to their students (Lynagh, Gilligan, \& Handley, 2010; Rothi, et. al, 2008; Walter, Gouze, \& Lim, 2006). Occupational therapists (OT) can work with adolescents to develop well-being, mindfulness, self-fulfillment, and participation in meaningful activities (Whiting, 2018). OTs can fill this treatment gap in our schools by implementing mindfulness and well-being programs that are evidence-based while teaching staff about self-regulation and the importance of their students' mental health (Sibinga, Webb, Ghazarian, \& Ellen, 2016; Tereda, 2017).

\section{Statement of the Problem}

Mental health of students is not being properly addressed in the school systems due the limited confidence of teachers and school staff to address these issues (Blackwell \& Billics, 2017; Lynagh et al., 2010; Rothi, et. al, 2008; Walter et al., 2006). While the school systems understand this is an area that should be addressed, there is a gap in providing these tools and skills to students. When students' mental health needs are not adequately addressed, it can be assumed that they turn to maladaptive methods of coping with what are otherwise overwhelming emotions and trauma. We see this in the high rates of drug and alcohol abuse in adolescents (CDC, 2019; Youth.gov, n.d.) and increasing rates of mental illness in late adolescence and adulthood (NAMI, 2019). While these methods may provide temporary relief, the long-term effects of high-risk behaviors can be assumed to contribute to the escalating cycle of these maladaptive coping and repeated traumatic incidents. Given the benefits of mindfulness and the negative impact of student stress and trauma, it was essential to explore the use of mindfulness techniques to address adolescents' needs in schools. 


\section{Purpose Statement}

This capstone project provided teachers with simple mindfulness and wellness strategies and tools to incorporate into their classrooms. These strategies gave students' healthy ways of coping with childhood traumas and other traumatic events. Occupational therapists can play a vital role in the administration of these strategies and help implement them into the school systems.

\section{Rationale for Proposed Project}

Mindfulness techniques are being used in many settings, especially in adolescent occupational therapy in the school systems (Bostic et al., 2015; Terada, 2017). Many studies (Sibinga et al., 2016; Terada, 2017; Zenner et al., 2014) have found that teaching students ways to be mindful and to think about well-being increases academic scores and decreases rates of depression, PTSD symptoms, and anxiety.

While we can see significant results of these interventions in academic and personal behavior, there is a lack of understanding and confidence in teaching mental health skills among staff and teachers (Blackwell \& Bilics, 2017; Lynagh et al., 2010; Rothi, et. al, 2008; Walter et al., 2006). This project's aim was to help teachers and staff address mental health needs in their classrooms and schools by providing basic knowledge and skills practice.

\section{Significance of Proposed Project}

This capstone project was comprised most significantly of product development but will also encompass aspects of program development, emerging practice, leadership and advocacy. The American Occupational Therapy Association [AOTA] (2018) asserts: “Occupational therapy can help all children develop and maintain positive psychological and social functioning, productive activities, and resilience in the face of adversity." Since occupational therapists' 
mental health training and skills may not be utilized in the school systems, students may miss out on key aspects of their mental health development, including self-regulation of emotions and mindfulness.

This capstone project looked at the implementation of mental-wellness and mindfulnessbased activities in the school systems through support from other professionals, classroom resources and activities, teacher-student relationships and peer relationships. Occupational therapists work closely with teachers, administrators, speech therapists, physical therapists, school psychologists, counselors, caregivers and students. This collaborative effort can provide holistic care to the students, giving them the greatest chance to be successful. The project took place at an elementary school, targeting a variety of classrooms in grades kindergarten through fifth grade. The project author met with school administrators and staff, observed and, gathered feedback from participating teachers/staff.

The potential outcome of this project was that the school systems would begin to feel more comfortable in their knowledge of mental health and would therefore incorporate mental health into their programs to equip students with the tools they need when they face adversity and other childhood trauma. Many adolescents may not know how to regulate their emotions or process traumas. If occupational therapists in the schools can give the school staff tools to properly and safely incorporate mental health into schools, it was assumed we would see a decrease in our adolescent mental illness rates and an indirect increase in sense of belongingness and academic scores.

\section{Connection to Theory}

Occupational therapy practitioners have been strong advocates for mental health since the beginning of the profession in 1920. AOTA (2019) describes that mental health is addressed in 
all interventions across all settings. Occupational therapists treat holistically, meaning that they treat the person as a whole, which includes the mental-wellness of the person.

The occupational adaptation model (Cole \& Tufano, 2008) can be used as a means to look at a person's mental wellness. It considers a person's ability to go through a situation, realize that something needs to change, and therefore change it in order to be successful. Adaptive capacity is the ability to recognize that something needs to change and to modify behavior in order to reach relative mastery. Reaching relative mastery is the ability for a person to look at his or her adaptive process and self-assess/reflect on if he or she reached the overall goal or not. This model relates to a person's mental health because it supports coping and appropriate self-regulation (Cole \& Tufano, 2008).

The cognitive behavioral frame of reference (FOR) (Cole \& Tufano, 2008) is also relevant to this area of practice. Cognitive behavioral FOR is all about self-awareness, selfregulation, and self-efficacy. Aaron Beck, a theorist who contributed to this FOR, focused his work on depression and understanding how distortions and automatic thought processes could lead to the maladaptive interpretations and conclusions about oneself. This is important because the way one thinks about oneself is often correlated to the mental-wellness and self-perception one has (Cole \& Tufano, 2008).

Another FOR that is relevant is the psychodynamic FOR, which incorporates-Sigmund Freud's perspective of the "personality structure" (Cole \& Tufano, 2008). Freud was a strong believer that what we experience as a child strongly effected our personalities when we are older. Research also suggests that experiences we have when we are younger shape our mentalwellness as adults (Cole \& Tufano, 2008).

\section{Preliminary Project Objectives}




\section{Product Goal}

Implement Mindfulness Toolkit into Lake Stevens, Washington Elementary School

\section{Product Outcome Objectives}

- Conduct a needs assessment through interviews, observation, and surveying of school faculty/staff on perceptions of mental health symptoms, coping, and mindfulness programs/products already in place

- Collaborate with school district administrators on program objectives and implementation to ensure long-term carryover of product materials and resources

- Implement the developed mindfulness product with at least five teachers at Skyline Elementary by Week seven

- Monitor implementation of product practices and carryover in the classroom by observing, interviewing, and surveying teachers/staff

- Participate in routine communication and training sessions with teacher/staff involved in the project throughout the six weeks of implementation, with at least weekly contact with each participating teacher/staff

- Evaluate results of effectiveness of product implementation by interviewing, observing, surveying, and obtaining written feedback from teachers/staff by Week 16

\section{Definition of Terms}

Holistic Care. Taking the whole person into account rather than just treating him or her as the diagnosis (Practicalnursing.org, 2019).

Mindfulness-Based Stress Reduction [MBSR]. "Is a blend of meditation, body awareness, and yoga: learning through practice and study how your body handles (and can resolve) stress neurologically" (Palousemindfulness.com, n.d.). 
Mental Health. How one handles emotions, feelings, and acts towards others, as well as deals with stress and how we make decisions (Mentalhealth.gov, 2017).

Mental Health Disorder/Mental Illness. A change in our emotions, thinking, behavior, or a combination ([APA], 2019).

Mindfulness. A practice that helps a person to be connected to his or her mind and body by breathing, focus techniques and centering (Tereda, 2017).

Self-regulation. The ability to consciously manage our emotions (Stosny, 2011).

Trauma. "An emotional response to a terrible event" such as natural disasters, motor vehicle accidents or other big events (APA, 2019).

\section{Assumptions}

It was assumed that simply by giving teachers and staff the means to incorporate mental health and well-being into their schools they would continue this practice. Often times, teachers have to prioritize other topics and lessons in the classroom as well as to fulfill state testing requirements. To eliminate the likelihood of no carryover, this project worked with five teachers, rather than directly with only five students. It was assumed working with the teachers themselves would achieve a greater likelihood of carrying over the tools and techniques learned in this capstone project.

\section{Conclusion}

Due to the knowledge of mental health statistics and the gap between educator's knowledge and implementation in their classrooms, the capstone project was created. In order to provide quality-based information and resources to individuals who would be involved in this project, a literature search was completed. This allowed the project to remain evidence based. In the following chapter, a review of peer reviewed articles, web pages, and other sources is 
completed in order to better understand how occupational therapy and mental health of students relate.

\section{Chapter II: Literature Review \\ Introduction}

Mental health encompasses many aspects, and many people are becoming more aware of the importance of good mental health and mental health practices. There are a number of professions that are able to address mental health in adolescents. Occupational therapists can do so within the school systems. Additionally, educators have a unique role in addressing the mental health needs of students because they are with them every day and therefore often witness early signs of mental health problems (National Alliance on Mental Illness [NAMI], 2019; Rothi et al., 2008).

This chapter of the capstone project proposal will provide an overview of school and life demands on students and how they contribute to mental health problems, review the work of occupational therapists in the school systems and their relationship with mental health interventions, consider the elements and benefits of mindfulness practices, and describe current mindfulness programs already in place throughout the country.

\section{Occupational Therapy in the Schools}

Occupational therapists have a special multi-dimensional role in the school systems, working with the students as well as teachers, other school staff, and caregivers. Occupational therapists can help students to participate in educational occupations in the classroom, cafeteria and during recess, such as writing, dressing, and play \& leisure (AOTA, 2019; Kaelin et al., 2019). The World Federation of Occupational Therapy (2016) also states that as occupational 
therapists, we should be promoting participation and well-being for students as well as promoting inclusive education.

\section{Inclusion}

The Individuals with Disabilities Education Act, or IDEA (2004) requires that students be in the "least restrictive environment" for learning. This federal law does not require inclusion into mainstream classes; however, it strongly encourages that students be placed in settings where they are most likely to get their needs met. This changed delivery services for schoolbased occupational therapists (IDEA, 2004). When IDEA came into play, occupational and other school therapists shifted their interventions from strictly working with students one-on-one to being able to work with teachers and whole classrooms.

One of the occupational therapists' main roles in the schools is to collaborate with teachers on how to best meet the needs of their students with special needs (Clark \& Chandler, 2013). More often we are seeing these students with more needs integrated back into the general education classrooms, creating an environment of inclusion (IDEA, 2004). Occupational therapists can help support these teachers, who now have students in their room who need more adaptations or accommodations, by giving them ideas to modify their classroom and to provide students with all the support they may need.

\section{OT and Mental Health}

Childhood trauma and toxic stress can often affect students' social interaction, play, academic scores, and emotional regulation (Whiting, 2018). As occupational therapists, work in the mental health field includes developing and promoting positive coping strategies, social interaction, and resiliency among individuals (AOTA, 2019). The OT profession can help to 
meet the mental health needs of individuals by developing new roles and routines, which can promote healthy lifestyles and encompass positive thinking and coping skills.

Occupational therapists can address these issues in the school by partnering with other school personnel to modify the environment, adapting testing and academic work, and consistently checking in with the teachers. Working directly with educators is vital to reaching students because teachers are often more tuned in to their students' emotional needs (National Alliance on Mental Illness [NAMI], 2019; Rothi et al., 2008).

\section{Schools and Students}

Students today in schools are dealing with much more than youth in the past had to endure. Students are completing state testing at a much younger age and many are aware of the very real traumas that happen in and outside of the schools around the country. These factors put more pressure on school systems to address mental health needs. Many teachers and school staff do not feel confident or comfortable addressing these issues with their students, nor have they had proper training (Blackwell \& Bilics, 2017; Lynagh et al., 2010; Rothi, Leavy \& Best, 2008; Walter et al., 2006).

Addressing mental health is a whole school problem (Ball, 2018). Research shows that while direct school services produce a greater impact on one student, addressing mental health holistically with every student in mind has a greater impact on the school as a whole and can help to reduce stigma of getting help (Sanchez et al., 2018). By addressing mental health as a school-wide issue, we as health care professionals and educators can hopefully be proactive, rather than reactive, in our services for the students.

Teachers have a unique relationship with their students and can be influential adults in these children's lives from a very early age. Since teachers are with their students approximately 
35-40 hours a week, they are able to notice when students might be struggling with anxiety, depression, or other mental health illnesses (National Alliance on Mental Illness [NAMI], 2019; Rothi et al., 2008). Giving educators the tools needed to address mental health will help reach more students than other school professionals can handle on their own.

Many individuals, such as psychologists, therapists, teachers, and even parents are creating a movement in their schools to address students' growing need for mental health services (Activate Alachua County Schools, 2018; Every Moment Counts, 2019; Mindful Schools, 2019). Though many are taking a stand to address the mental health needs of students, there is still an increasing crisis and need for additional mental health services in schools (National Association of School Psychologists, 2019).

\section{Mindfulness and Mental Wellness}

Poor mental health is a very common problem in the United States. Rates of mental illness are rising in both children and adults (CDC, 2019; HHS, 2018). Mental health is commonly defined as our emotional state of being, and incorporates our thinking, feelings, and reactions to our environment (Mentalhealth.gov, 2017). When someone is in "good" mental health, he or she is able to appropriately cope with adversities and is essentially "free" of mental illness.

One in five children between the ages of 9 and 17 has an emotional or behavioral disorder (Koppleman, 2004) and serious emotional disorders affect approximately 4\%-13\% of the U.S. population aged 4 to 17 years (CDC, 2019; Clark \& Chandler, 2013). Common emotional disorders that we see in children are depression and anxiety, and it seems that more and more children are getting diagnosed. However, it can be assumed while the rates of childhood mental health issues continue to rise, awareness about the issue has not followed in its footsteps. 
Stress is a part of our everyday lives, even for children. There is a fine line between healthy and toxic levels of stress (Franke, 2014). In today's world, societal, academic, and familial standards may bring children toxic levels of stress. These have very real neurological and physical effects on their bodies (McGonigal, 2013; Mindful Schools 2019; National Geographic, 2015). The ongoing "fight or flight" response (National Geographic, 2015) is often seen as "behavior issues," ADHD, depression, and anxiety in today's youth. Current practice for addressing mental health disorders commonly includes medication and psychological services (Mental Health America, 2020). However, other cultures use non-pharmacological approaches to reduce stress, which are starting to become more popular here in the U.S. The use of mindfulness-based strategies is one of these practices making its way into mainstream treatment for stress and mental health issues (Chiesa \& Seretti, 2009).

Mindfulness can be defined as a practice that helps one to be connected to his or her mind and body by breathing, focus and centering techniques (Tereda, 2017). Mindfulness has been proven to decrease the rates of these behavioral and emotional disorders, as well as to increase physiological functioning as a whole (Zenner et al., 2014). This approach is both safe and simple to implement with children and may provide another option for addressing the mental health needs of our youth.

\section{Current Practices}

Activate Alachua County Schools (2018) is a mindfulness movement started by one mother, who is also an occupational therapist, in response to the Parkland, Florida school shooting in 2018. Her team has created more mental health awareness in public schools. They believe that much of the change that is needed in schools starts directly with the students themselves (Activate Alachua County Schools, 2018). In an article by Schall, LeBaron Wallace, 
\& Chhuon (2016), 34 students were interviewed regarding their perceptions of their social status and ability to control feeling like they fit in. The study showed that students who had a lower level of social connectedness had a lower level of perceived control of their social status. The need for connection is an innate characteristic. When students feel disconnected from their peers and teachers, they are less likely to seek help in positive, healthy ways, and often turn to other substances or behaviors for coping. Offering teachers ways to promote peer interactions and open up doors for communication will positively impact the way students behave and interact (Schall et al., 2016).

Every Moment Counts (2019) is a program that was created by Susan Bazyk, a professor who strives to continue to work in the mental health field. Her mission is to integrate mental health promotion into schools for youth, to increase success in the school systems, home life and in the community. The main goals of this program are to change the stigma about mental health and encourage conversations about mental health. Part of her program includes creating a comfortable cafeteria atmosphere, a refreshing recess time and other after school activities. She believes it is important to address mental health in academic and non-academic activities alike to produce carryover of learned behaviors. This initiative takes everyone's full effort to change the atmosphere of their school: teachers, staff, students, parents, and community members (Every Moment Counts, 2019).

A TED talk by Kelly McGonigal (2013) suggests that thinking that stress is bad for us is actually worse than the stress itself. She explains that changing the way we think about stress changes how our bodies respond to stress. There were two studies done that looked at participants' stress events and their responses to those events. The first study (Jamieson, Nock, \& Mendes, 2012) tracked 30,000 adults over eight years, asking them how much stress they had 
experienced in the past year and if they thought this stress was harmful for them. Using public records, the study concluded that the people who experienced high stressors had a $43 \%$ increased chance of dying prematurely. However, this was only true for the people who believed that stress was harmful to their health. The researchers taught the participants how to view their stress response as helpful to their performance, rather than harmful (Jamieson et al., 2012). The second study (Poulin, Brown, Dillard, \& Smith, 2013) looked at how much stress each person experienced in the past year and how much time he or she spent helping others. For every major stressful life event, the risk of dying prematurely increased by $30 \%$; however, the participants who spent time helping others had absolutely no increase in risk of stress-related deaths (Poulin et al., 2013). These studies' results emphasize how powerful our minds are and how important it is to have positive interactions with others. Caring for others can create resilience among people, and how we choose to view our stress response can help to elongate our lives and better our health. This information, along with Every Moment Counts movement can be used to shift our thinking to be more positive and healthier.

Mindful Schools (2019) is another nationwide organization that helps to bring mindfulness into classrooms. This organization started in 2007 in one California classroom. Its goal is to integrate mindfulness practices into everyday life of schools and to transform the schools from the inside out. Mindful Schools provides educators and youth service providers with the tools they need to address mental health. The organization believes that using mindfulness can help to improve attention, emotional regulation, and compassion among students as well as decrease students' stress and anxiety. During the 2011-2012 school year, researchers sponsored by Mindful Schools taught 47 teachers in the Oakland Public Schools about their mindfulness curriculum and provided them with tools to teach their 937 students. 
Classrooms led by teachers who had completed the mindfulness courses produced statistically significant improvements in the student's attention and participation, more so than classrooms where a handful of students were directly taught mindfulness (Mindful Schools, 2019). This supports the assumption that educating teachers and school staff about the importance of mindfulness and how to incorporate it into their system will have long lasting effects on students.

In addition to bringing mindfulness into the classrooms, many individual schools and teachers have created a space within their classroom where students can use different mindfulness tools when upset or needing a space to step away to. There are many names for this space, including "calming corners" and "safe spaces". While there is not ample research conducted with studies, it is still a common practice in schools as seen through a simple internet search on the topic. This is not a space used to punish the students, rather to provide the opportunity to engage in calming activities and bring them back to a grounded state of mind (A Quiet Place for Tough Moments, 2003). Using these spaces have been shown to help regulate physical and emotional states of students (Calm Down Corners, 2018). Many of these spaces are implemented in schools in response to trauma informed practice and adverse childhood experiences (ACES) by creating a 'trauma-sensitive space" within the student's environment (Calm Down Corners, 2018).

\section{Benefits of Mindfulness}

\section{Mindfulness Changes the Brain}

There are very real physical responses to stress, anxiety, and trauma. Research has shown that the same can be true when looking at mindfulness. Mindfulness can change the structure and electrical activity in our brain in positive ways to help counteract what has been done by stress and poor mental health. 
A part of our brain called the amygdala is responsible for identifying and reacting to emotions such as fear (Neuroscientifically Challenged, 2014). Research shows that after completion of mindfulness training, the amygdala is less active and therefore the fear response decreases (Lutz, Slagter, Dunne, \& Davidson, 2008).

A second area that is affected during mindfulness practices is the hippocampus, which is involved in learning and memory (Brain Made Simple, 2019). A study by Goldin and Gross (2010) found that following mindfulness-based stress reduction (MBSR) training this area of the brain was found to be more active.

\section{Benefits in Students}

Mindfulness has been shown to improve students' attention span while working on tasks that require higher cognitive thinking and concentration (Chiesa, \& Serretti, 2009; Bostic et al., 2015; Sedlmeier et al., 2012). Mindfulness techniques have also been found to improve emotional regulation and social skills among peers (Metz et al., 2013; Schonert-Reichl et al., 2015). After a Mindfulness curriculum was implemented into schools across the nation, teacher survey results indicated that $89 \%$ of students had improved emotional regulation, $83 \%$ had improved focus, and 79\% showed greater engagement while in the classroom (Mindful Schools, 2019).

Courses such as MBSR can be an effective way of teaching individuals about mindfulness and how to cope with stress in our lives. Mindfulness training has been proven to effectively lower rates of depression, anxiety, stress, and negative coping habits in students (Chiesa, \& Serretti, 2009; Sibinga et al., 2016; Tereda, 2017).

\section{Benefits for Educators}


Mindfulness also has a great positive impact on educators. Research shows that teachers who participate in mindfulness have reduced stress and burnout rates (Flook, Goldberg, Pinger, Bonus, \& Davidson, 2013; Jennings, Frank, Snowberg, Coccia, \& Greenberg, 2013; Roeser et al., 2013). When educators completed online mindfulness training, $90 \%$ reported lower stress and greater self-compassion and 77\% were more satisfied with their jobs (Mindful Schools, 2019).

Teachers who practiced mindfulness also saw a change in their classroom atmospheres. Students and teachers became more supportive of each other and of their classroom environment (Jennings et al., 2015). When teachers completed mindfulness courses, $82 \%$ reported connecting better with students and $80 \%$ reported they could deliver curriculum with more ease than before (Mindful Schools, 2019).

\section{Conclusion}

Adolescents today have to cope with very real-life stressors and traumas. Many turn to unhealthy and short-term coping strategies that will have negative long-term effects. Professionals and organizations have taken a stand to help address the rising mental illness epidemic by creating safe spaces, developing mental health awareness programs and incorporating mindfulness practices. Mindfulness is a tool that works to help make an individual aware of his or her body and surroundings. While it is clear that mental health needs to be addressed in school systems, many educators do not feel confident enough in their abilities to do so. That gap ultimately brought rise to this capstone project.

\section{Chapter III: Project Description}

\section{Introduction}


This capstone project served the purpose of bridging the gap between educators' knowledge of mental health and providing these services to students, grades K-5, with confidence and ease. The project began with a needs assessment at a local elementary school to understand the needs of both the school as a whole and of individual students. It was at this same elementary school that five teachers participated in the project, which included the implementation of a mindfulness toolkit. The mindfulness toolkit was based on the needs assessment conducted with a variety of professions in the elementary school. Data from the project came from interviews, observations, and informal writing prompts. The potential outcome of this project was that school staff would begin to feel more comfortable regarding their knowledge in mental health and would incorporate mindfulness into their classrooms in order to equip the students with the tools that they need for the future.

The following outcome objectives guided the steps and process of the project as well as product development throughout the project:

1. Conduct a needs assessment through interviews, observation, and surveys of school faculty and staff on perceptions of mental health symptoms, coping, and mindfulness programs and products already in place.

2. Collaborate with school district administrators on product objectives and implementation to ensure long-term carryover of product materials and resources.

3. Implement the developed mindfulness product with at least five teachers at Skyline Elementary by week seven.

4. Monitor implementation of product practices and carryover in the classroom by observing, interviewing, and surveying teachers and staff. 
5. Participate in routine communication and training sessions with teacher/staff involved in the project throughout the six weeks of implementation, with at least weekly contact with each participating teacher and staff.

6. Evaluate results of effectiveness of product implementation by interviewing, observing, surveying, and obtaining written feedback from teachers/staff by week 16 .

\section{Process \& Methods}

\section{Participants}

The project participants consisted of five elementary school teachers and two speech language pathologists at Skyline Elementary School in Lake Stevens Washington. All teachers despite years of experience or teaching area participated. Participation in the project was voluntary, and it was assumed that teachers would complete all six weeks of planned training and activities. Interviews and classroom observations with these teachers were held throughout the duration of the project to assess effectiveness of the Mindfulness Toolkit.

\section{Setting \& Measures}

This project took place at Skyline Elementary School in Lake Stevens, Washington. Each participating classroom at the elementary school used the toolkit. Conducting this project within the elementary school allowed for the implementation to take place within the student's natural environment.

A needs assessment at the beginning of the project provided data in order to best understand the needs of the school and teachers. Another needs assessment during the implementation phase of the project provided data that allowed for additional resources to be developed. The data emerged through interviews and email with a variety of professions 
involved with students in the school system. Both needs assessments were the driving factor in the chosen mindfulness-based activities that were used in the Mindfulness Toolkit.

Each week, the participating teachers filled out and turned in a 'reflection journal' [Appendix A] based on those weeks' activities. This reflection journal did not have any identifying features of students, and simply served as a method for providing teachers and the program lead feedback for future enhancements to this project. Teachers received a handout that included six mindfulness activities that they were to incorporate into their classrooms throughout the implementation stage of this project.

\section{Development Process}

This project was created as a direct result of a literature search on mental health in schools and mindfulness strategies. The searches revealed a gap in the literature; while educators agreed that addressing students' mental health is important, many did not feel confident in implementing those practices in the classrooms (Blackwell \& Bilics, 2017; Lynagh et al., 2010; Rothi et al., 2008; Walter et al., 2006). This gap was addressed through the development of Mindfulness Toolkit for K-5 teachers at Skyline Elementary School.

In addition to a literature review, many staff members from the elementary school were interviewed and asked what they thought would be most beneficial for teachers in the schools to address mental health. General education and special education teachers, occupational therapists, physical therapists, school counselors and academic advisors provided input into this project and the Mindfulness Toolkit. All of these professionals were recruited from Skyline elementary school staff.

After the needs assessment and interviews with professionals were completed, a search was conducted for specific mindfulness activities to use in the classrooms. The goal was to 
identify six different mindfulness activities that have been proven to have direct positive effects on students and classrooms. This helped to keep the Mindfulness Toolkit evidence-based. This toolkit includes information directly found both in the literature as well as through the needs assessment with school personnel.

Next, teachers needed to be identified who would be willing to participate in the project for seven weeks total. Attending staff meetings, school wide emails, and individual meetings helped to generate participant interest. A simple sign-up sheet was used to recruit interested teachers.

\section{Implementation Process}

This capstone project was completed over 14 weeks total, including establishing relationships, conducting a needs assessment, implementation, and debriefing at the conclusion of the project. Relationships with teachers and other school staff developed through attending staff meetings, classrooms observations, and reaching out to teachers throughout the course of the capstone project. A needs assessment helped to identify the gap between 'what is' and 'what should be' (Office of Migrant Education, 2001). This assessment also helped to plan for future action regarding mental health in schools.

The implementation of this Mindfulness Toolkit with K-5 teachers took place over a total of six weeks, where teachers had the opportunity to implement six different mindfulness themes. The mindfulness activities included breathing exercises, awareness of heartbeats, focusing on senses, body awareness and mindful movements, as well as identifying emotions and positive affirmations (Sibinga et al., 2016; Tereda, 2017). Both the deep breathing and heartbeat exercises helped student learn how different movements and activities affect our breath and heart rate. Students completed a variety of activities while focusing on their breath. Being aware of physical 
surroundings is another way that can help students to be more mindful. The body uses five senses to connect with our surroundings; sight, sound, smell, taste, and feeling. Focusing on the five main body senses helps students to stop and focus on what is going on around them in their immediate environment. Another activity that was included was teaching students about body awareness and being mindful with their movements. Positive affirmations were incorporated to help build resilience in students, as well as to show that words have an impact. Lastly, identification of emotions was also introduced in the classrooms. This activity taught students the importance of being aware of how they may be feeling, and also helped to teach them selfregulation. Each week had an introduction to the mindfulness activity to properly prepare the teacher to share the activity with their classroom. Each week, the doctoral student checked in with the teachers by email or in person during observations. These weekly meetings helped to ensure understanding and comfort level of the participating teacher and to answer any questions they may have had.

Additionally, each week the teachers filled out a brief 'reflection journal' that helped consolidate information and feedback. This reflection journal was a template with simple prompted questions regarding how each activity was perceived to impact their students, what changes in environment they saw, changes in peer interaction and anything else they wished to include. The teachers stated what they would change, if anything, about the activity. This information helped to evaluate the perceived effectiveness of the toolkit.

\section{Evaluation Component}

At the completion of the six weeks, a debriefing session with all participating teachers was going to take place to discuss the effectiveness of the mindfulness toolkit. However, due to unforeseen circumstances the final meeting and the collection of the reflection journals were did 
not occur. Therefore, the reflection journals from all teachers could not be reviewed and sorted by activity. The reflection journals would have helped continue to support the need of mental health in schools by incorporating teacher feedback into future iterations of this project. A debriefing session was also unable to occur with each of the participating teachers to facilitate a conversation about the mindfulness toolkit and the overall effectiveness of the capstone project. Instead, informal verbal feedback was collected.

\section{Alignment with Objectives}

Each program outcome objective was guided with the project timeline in mind. The methods and process described above helped with the successful completion of the objectives at both the midterm and final weeks of the project.

To achieve objective number one and two, interviews with interested educators and staff, informal observations of classrooms, and surveys of other professionals in the school and community were included. The information gathered from these sources helped to develop the mindfulness toolkit so that it best aligned with the established needs. Additionally, collaboration with school administrators and site supervisors on all objectives took place to ensure long-term carryover of the product and resources.

The implementation phase of the project addressed objectives three through five. Each participating teacher received a mindfulness toolkit and an explanation of the toolkit to ensure understanding of the materials. Weekly check-ins, observation in classrooms, and communication with both teachers and site supervisors supported understanding of material.

Lastly, objective six was unable to be directly addressed at the conclusion of the implementation and throughout the last weeks of the capstone project due to unforeseen circumstances. 


\section{Conceptual Framework}

The intent of this project was to serve a handful of elementary school teachers, to then benefit students immediately, by receiving mindfulness-based practices in the classroom, and also to benefit the school as a whole by addressing the mental health needs of students. An assumption in this project was that at least five teachers would be willing to participate and complete all six weeks of the activities. The project took place at a local elementary school with general education classrooms in the Lake Stevens School District.

A challenge in this project was the limited time that teachers have to incorporate new activities or lessons into their day. Demands on teachers are high, and it is possible that teachers would not want to participate because of this barrier. To eliminate this challenge, this project required teachers to incorporate a variety of activities that only required a short amount of time. The educators also were able to choose the time of the day to do the activities.

Each participating teacher received a mindfulness handout with an introduction to mindfulness and each mindful activity, six mindfulness activities to complete within the classroom setting, and six journal reflections for the teachers to individually complete. Since the activities in the Mindfulness Toolkit were already planned, greater willingness to participate was anticipated among teachers. An assumption of this project was that through theses mindfulness activities, students' well-being and mental health would improve. Through this, it was possible that an increase in social skills, academic performance and peer interactions would occur, while a decrease in depression, anxiety, and stress would also occur. This project included direct interaction with educators rather than with students. This allowed for the impact of the project to carryover to consecutive school years, which should impact many more students than this project alone would be able to reach. 


\section{Timeline}

\section{Needs Assessment}

A needs assessment with school staff and schoolteachers at Skyline Elementary was necessary in order to meet their specific needs. Within the first two weeks of the project, staff meeting attendees received an introduction to an overview of the proposed project. This served the purpose of opening up the conversation with teachers and allowing them to think of questions they might have. Meeting with site supervisors to discuss needs and gaps in addressing mental health in their school also took place in the first two weeks. During weeks two through four, observations took place in classrooms, in addition to various other professionals' settings such as the school counselor, speech therapist and occupational therapists' groups. Meetings with other school staff also took place to observe what was already being done in the school to address students' mental health needs. During weeks five and six, five teachers were acquired to participate in the project through a staff meeting.

A second needs assessment with the school principal and all participating teachers and staff during the implementation phase of the project took place to address any other mental health needs of the students and school. This needs assessment concluded that the school needed additional resources on 'calming corners' as well as de-escalation techniques to use with students who have anxiety and other mental illnesses/concerns.

\section{Implement the Developed Mindfulness Product}

Week seven was used to meet with participating educators to hand out the mindfulness activities. During this week, participants walked through each mindfulness activity to ensure understanding. The implementation phase lasted through week 13, with each classroom introducing a mindfulness activity each week. 
Week seven through 13 documents created in response to the findings from the second needs assessment were established. Collaboration with various professions and a literature search provided the school with current evidence-based practices on these topics.

\section{Monitor Implementation of Program Practices}

Weeks eight through 13, check ins with each participating teacher included both emails and in person, to ensure understanding of each activity and open up the space for questions. Additionally, participating teachers filled out 'reflection journals' each week to give feedback about the activity and to describe what they observed in their classroom during the activity. Observations in the classrooms also took place during weeks eight through 13.

\section{Evaluate Results}

Reflective journals and an in person debriefing meeting were to take place at the completion of the project timeline, however, due to unforeseen circumstances, the written and verbal feedback was unable to be obtained to complete the project data collection.

\section{Conclusion \& Next Steps}

There is a great need for mental health to be addressed in adolescents due to the rising number of students who are at risk for developing mental health issues (HHS, 2018). Mindfulness is one tool that students and schools can use to address the mental health needs of students and the community. Mindfulness has been shown to improve the social and peer interactions in children and to improve coping skills, as well as decrease the rates of anxiety and depression in students (Sibinga et al., 2016; Terada, 2017; Zenner et al., 2014). Through the implementation of the mindfulness toolkit, an assumption was that this capstone project would help to address the mental health needs of students by giving teachers the needed tools to do so. After the completion of this project, the intent is that the participating teachers will feel more 
confident in addressing mental health through mindfulness activities in their classrooms and continue to utilize the tools given to them in consecutive school years, which should impact more and more students over the years.

\section{Chapter IV}

\section{Product}

This project started with a needs assessment with various school personnel and teachers on the mental health and mindfulness needs at Skyline Elementary. School personnel such as school counselors, behavior specialists, teachers, administrators and occupational and speech therapists were all involved in this assessment. Each responded to questions about would be perceived as the most beneficial tools to distribute to the participating teachers. The results from the needs assessment showed that the staff and teachers needed assistance with implementing mindfulness activities into their classrooms. Through research on the internet and by conducting a literature review, six different mindfulness themes emerged to present to participating teachers at Skyline.

A staff meeting at the beginning of the project recruited possible participating teachers and staff. A total of 14 educators signed up to learn more about the project and the requirements associated with the project. Interested teachers and staff received an email including time requirements and projected outcomes. A second meeting was held with a total of five teachers and two other school professionals who volunteered to implement the mindfulness toolkits within their classrooms and small groups. At this meeting each individual received all materials, including the toolkit and all associated materials and activities. Additionally, the participating teachers walked through the toolkit in its entirety and had the opportunity to ask questions prior to implementing the toolkit within their classrooms. 
Following distribution of the materials, the teachers implemented the toolkit with their students over the next six weeks. Emails and observations took place throughout the implementation to continuously check in with the participants. During observations, student reactions and perceived effectiveness of the activity were noted. Based on the observations in the classrooms, changes to the toolkit occurred. Changes such as instructions made clearer, examples of worksheets added to the end of the toolkit for future implementation, as well as a suggested activity 'script' to guide the teachers in introducing the activity. These changes were vital to make to increase ease of implementation and reduce stress surrounding the implementation of the various mindfulness activities.

During week three of the implementation phase, a second needs assessment inquired about other mental health needs the school had. Through this assessment, schoolteachers stated they needed a document to help coach when interacting with students who have anxiety and other behavioral issues, as well as a document discussing the 'calming corner' initiative recently implemented within the school. Another literature search gave rise to two other separate documents as well as discussion with professions such as behavioral experts, principals, and counselors. The de-escalation document helped to give educators a clear set of "how to" when dealing with a student who is becoming escalated. While educators in Lake Stevens School District do complete a training on this online, this document supplemented the learning from those trainings as well as directly related it back to mental health needs. The "calming corner" document was created to give teachers and other school staff tips to implementing and using a calming corner within their classrooms. This document included a brief introduction to the corners and background of their use, a set of calming tools that they could include in their corners, and other suggestions on using the space with students who need clear instructions and 
more defined rules. After the creation of the two documents, all school personnel received them through the online sharing platform that the school district uses.

Throughout weeks three through six of the implementation phase, various videos were created regarding the mindfulness activities. These videos will be able to be accessed by future educators and staff who wish to implement the toolkit. These videos include a brief background and importance of the activity and suggestions on how to implement each activity. The Emotions Wheel and 5,4,3,2,1 Activity videos also included suggestions on how to guide the students in filling out the worksheets. These videos will help with future carryover of the mindfulness toolkit with other schools and other districts.

Due to unforeseen circumstances, during week 13, the Lake Stevens School District was mandated to close and move to virtual learning for an undesignated amount of time. Nearing the completion of the project, two meetings were to be held, one with all principals from the district and one with the entire special education team at Skyline Elementary. These meetings were going to serve the purpose of discussing the outcomes of the project as well as attempting to create carryover of the project into other schools within the district and with other educators. While at this time these meetings have been cancelled, there are plans to conduct these meetings and presentations at a later date, once the district resumes the school year.

In response to this change, an addendum was provided to the educators as an additional resource for teachers and school staff to share with students and families. This resource was a 3page flyer on mindfulness amidst a health crisis and included coping strategies, two online resources for families specific to the national health concerns currently, as well as the breathing activities and the 5,4,3,2,1 activity from the Toolkit.

\section{Measurement of Effectiveness}


Throughout the six weeks of implementations, the participating educators were given reflection journals where they were to write observations of their classrooms, rate each activity, and give feedback on each activity. Each mindfulness activity had its own reflection journal, totaling six, and were to be handed to the doctoral student at the completion of the project. All attempts were made to contact participating teachers through email in order to gather these reflection journals, however they were unable to be collected at this time because of greater priorities the teachers and staff at Skyline Elementary School are facing at this time.

A one-hour debriefing session was also planned to take place. However, this was unable to occur due to the unforeseen national health emergency. Teachers will be reached out to over email to attempt to gather any feedback they have at a later date, once the project has already come to completion.

While no written feedback was able to be obtained, a fair amount of verbal feedback was collected from teachers, staff, and students. One fourth grade student expressed that the quiet sit pose of the Mindful Movements activity was his favorite because it "helped [him] calm down his body and feel relaxed'. Many of the students and teachers expressed enjoying the mindful breathing exercises and continued to incorporate this activity throughout their school day, despite introducing the next mindful activity in various weeks. Many students were also heard asking their teachers for more activities or videos online.

Teachers exclaimed that they too enjoyed introducing the activities that they have "seen changes already within [the] classroom". Some educators also reported that the Mindfulness Toolkit helped with the ease of implementation and that they enjoyed the introduction to each mindfulness theme. Educators also stated that future changes would benefit the toolkit such as a suggested script and specific activity ideas, as well as a video that walked through the toolkit. 
These suggestions guided the modification of the toolkit as well as provided additional resources for the Elementary School.

Through various observations completed, it was noted that many of the classrooms enjoyed the mindful breathing exercises and the mindful movement activity best. This can be attributed to the ease of implementation and little additional work needed by the teacher to complete the activity.

\section{Results and Discussion}

\section{Results of Project}

Despite having a change in the projects feedback system, the results of this project and implementation of the mindfulness toolkit did not change. The participating teachers, staff members, principals, and other school personnel all expressed that this project helped to meet the needs of many students in their elementary school. This Mindfulness Toolkit helped bring teachers the needed resources and confidence to introduce mindfulness practices within their classrooms, despite grade level. The creation and of this toolkit allowed teachers to positively and successfully introduce their students to mindfulness practices with ease.

\section{Implications for Profession of Occupational Therapy}

Mental health is an underserved area of need for many. The results of this capstone project imply that the need for teachers to be supported in the introduction and implementation of mental health practices is there. This project also showed the importance of occupational therapists' role in supporting student's mental health. Many students are unable to concentrate on and complete schoolwork if they are dealing with mental health issues. Occupational therapy looks at the student in a holistic manner, making connections between their mental health and access to their education. It can be assumed from this project that there is a need for more 
classroom services in order to serve students successfully. Therefore, OTs can help to implement these practices with schools and groups of students while staying within their scope of practice.

\section{Limitations and Delimitations}

\section{Limitations}

Two limitations of this project were that only five teachers in one school participated. The hope is that those five teachers will continue to use the mindfulness toolkit to consistently address mental health with their students year after year, thereby reaching many more students over time. Since the time period for implementation was also limited to eight weeks total, focusing on one school made more sense for this project. This project only worked with five teachers in one school, versus being able to reach a larger number of participants in multiple schools in multiple districts over a longer period of time. Because participation in this project is voluntary, another limitation was that there was not equal participation in grade level among teachers.

Other limitations of this project included lack of resources and support. Because the graduate student completing this project was not employed by the school system, it was difficult to get in contact with school staff and administrators. To help mitigate this limitation, a partnership was established with two site supervisors who are employed by the district and located at the elementary school where the project took place. They supported the primary researcher by contacting other school staff and administrators as needed.

Lastly, another limitation of this project was the possible lack of funding for the future. It was the hope that this program will continue on in the elementary school and be expanded to other schools in the district, as well as in surrounding districts.

\section{Delimitations}


One delimitation of this capstone project was the choice to complete the mindfulness study in an elementary school. To gather accurate and useful feedback at the end of the project, teachers in all grade levels were encouraged to participate. There were no other known delimitations for this project.

\section{Chapter V}

\section{Summary of Previous Chapters}

In previous chapters one and two, background on the mental health dilemma in public schools has been explored as well as a literature search was conducted on the gap between educator's knowledge on mental health needs of their students and their confidence in addressing this topic. Chapters three and four included a thorough walk through of what was completed with this capstone project, including a needs assessment, specific individuals who gave input throughout, as well as changes that occurred and why. In this chapter, future considerations will be explored as well as a conclusion to this capstone project.

\section{Future Considerations}

There are a few future considerations and applications to keep in mind at the conclusion of this capstone project. In the future, it is suggested that feedback be given throughout the implementation phase rather than all at once at the completion of the six weeks. This will allow for feedback to be collected and reflected upon in the moment, while also eliminating the possibility of not being able to collect feedback due to unforeseen circumstances.

Additionally, it is recommended to conduct a research study on the use of the activities in the Toolkit. While there was verbal feedback that the Toolkit provided adequate instruction and activities to address the mental health crisis, more research is needed to prove validity and true effectiveness of the product. It is also suggested that in the future a study involving more 
educators and staff across multiple grade levels be conducted. Because this capstone project was voluntary, there was not equal participation among grade levels. A future implementation across multiple schools and districts is also recommended to continue to spread the Mindfulness Toolkit and its resources beyond Lake Stevens, Washington.

\section{Conclusion}

Mental health in adolescents is still of great concern, with the numbers quickly rising by each decade (Healthy Youth Survey, 2018; US Department of Health and Human Services [HHS], 2018). Something needs to be done in order to halt the progression of these numbers in our country and world-wide. The hope is that this doctoral capstone project can be added to the many movements attempting to bring about change in addressing mental health. While this product was completed only with a small town in Washington State, many more occupational therapists were also able to reap the benefits.

Due to the nature of this project and the additional resources that were created due to unforeseen circumstances, many other occupational therapists and their clients and students were impacted. Resources were shared in an online Facebook group for occupational therapists in the school setting. This allowed some of the additional resources to be shared nationally among thousands of other OT's, having an even greater impact than anticipated at the start of this project.

Within the school where the Mindfulness Toolkit was completed, many other professions than occupational therapy were impacted. Administrators such as the principal saw the importance and need by the teachers for a product such as this to implement with their classroom. Teachers were impacted by seeing a difference in their classrooms behaviors and attention levels to seated tasks. The relationship between teaching staff and support staff, such as 
occupational therapy, was also strengthened by this product. The occupational therapists that were involved in this project were impacted by being involved with new research and were left with the Mindfulness Toolkit as a resource for many more years to come.

The growing need and interest in mindfulness-based practices in the school setting is growing, seen by numerous movements created by individual parents, teachers, and professions. This project successfully left one school the tools that they needed in order to implement six of these practices with their students. It is anticipated that this need will continue to rise, and that this project will help to inspire many more doctoral students, school administration and staff, and parents to continue addressing their students mental health needs and teach them the tools that they need to be successful in their education as well as their everyday lives. 


\section{References}

A Quiet Place for Tough Moments. (2003). Retrieved from

https://www.responsiveclassroom.org/a-quiet-place-for-rough-moments/

Activate Mental Health \& Wellness in Alachua County Public Schools. (2018). Retrieved from https://www.activatealachuacountyschools.com

American Occupational Therapy Association (AOTA). (2019). School-based practice. Retrieved from https://www.aota.org/Practice/Children-Youth/School-based.aspx

American Occupational Therapy Association (AOTA). (2019). Mental health. Retrieved from https://www.aota.org/About-Occupational-Therapy/Professionals/MH.aspx

American Psychological Association (APA). (2019). Trauma. Retrieved from https://www.apa.org/topics/trauma/

American Psychological Association (APA). (2019). What is mental illness? Retrieved from https://www.psychiatry.org/patients-families/what-is-mental-illness

Ball, M., A. (2018). Revitalizing the OT role in school-based practice: Promoting success for all students. Journal of Occupational Therapy, Schools, \& Early Intervention, 11(3), 263272. doi: $10.1080 / 19411243.2018 .1445059$

Blackwell, C. D. \& Bilics, A. (2017). Preparing occupational therapy students to address mental health promotion, prevention, and intervention in school-based practice. Journal of Occupational Therapy, Schools \& Early Intervention, 11(1), 77-86.

doi:10.1080/19411243.2017.1386605

Brain Made Simple. (2019). Hippocampus. Retrieved from https://brainmadesimple.com/hippocampus/ 
Bostic, J. Q., Nevarez, M. D., Potter, M. P., Prince, J. B., Benningfield, M. M., \& Aguirre, B. A. (2015). Being present at school: Implementing mindfulness in schools, Child Adolescent Psychiatric Clinic of North America, 24(2), 245-259. doi.10.1016/j.chc.2014.11.010

Calm Down Corners. (2018). Retrieved from http://safeschoolsnola.tulane.edu/safe-andsupportive-classrooms/calm-down-corners/

Centers for Disease Control and Prevention (CDC). (2019). Adverse childhood experiences (ACEs). Retrieved from https://www.cdc.gov/violenceprevention/childabuseandneglect/acestudy/index.html Centers for Disease Control and Prevention (CDC). (2018). Data and statistics on children's mental health. Retrieved from https://www.cdc.gov/childrensmentalhealth/data.html Centers for Disease Control and Prevention (CDC). (2019). Teen substance use and risks. Retrieved from https://www.cdc.gov/features/teen-substance-use/index.html

Chiesa, A., \& Serretti, A. (2009). Mindfulness-based stress reduction for stress management in healthy people: A review and meta-analysis. The Journal of Alternative and Complementary Medicine, 15(5), 593-600.

Clark, G. F. \& Chandler, B. E. (2013). Best practices for occupational therapy in schools. Occupational Therapy Association.

Cole, M. B. \& Tufano, R. (2008). Applied theories in occupational therapy A practical approach. Thorofare: SLACK Inc.

Every moment counts. (2019). Retrieved from https://everymomentcounts.org

Flook, L., Goldberg, S. B., Pinger, L., Bonus, K., \& Davidson, R. J. (2013). Mindfulness for teachers: A pilot study to assess effects on stress, burnout, and teaching efficacy. Mind, Brain, and Education, 7(3), 182-195. 
Franke, H. A. (2014). Toxic stress: Effects, prevention and treatment. Children (Basel), 1(3), 390-402. Doi:10.3390/children 1030390

Goldin, P. R., \& Gross, J. J. (2010). Effects of mindfulness-based stress reduction (MBSR) on emotion regulation in social anxiety disorder. Emotion, 10(1), 83.

Healthy Youth Survey. (2018). Youth mental health in Washington state [PDF file]. Retrieved from https://www.askhys.net/Docs/Youth\%20Mental\%20Health\%20in\%20WA\%20State.pdf Individuals with Disabilities Education Act. (2019). Retrieved from https://sites.ed.gov/idea/statuteregulations/

Jamieson, J. P., Nock, M. K., \& Mendes, W. B. (2012). Improving acute stress responses: The power of reappraisal. Current Directions in Psychological Science, 1-6. doi: $10.1177 / 0963721412461500$

Jennings, P. A., Brown, J. L., Frank, J. L., Doyle, S. L., Tanler, R., Rasheed, D., ...Greenberg, M. T. (2015). Promoting teachers' social and emotional competence, well-being and classroom quality: A randomized controlled trial of the CARE for Teachers Professional Development Program. In C. Bradshaw (Ed.), Examining the impact of school-based prevention programs on teachers: Findings from three randomized trials. Washington, D.C: Symposium presented at the Society for Prevention Research Annual Meeting (Submitted for Initial Review).

Jennings, P. A., Frank, J. L., Snowberg, K. E., Coccia, M. A., \& Greenberg, M. T. (2013). Improving classroom learning environments by cultivating awareness and resilience in education (CARE): Results of a randomized controlled trial. School Psychology Quarterly, 28(4), 374-390. 
Kaelin, V. C., Ray-Kaeser, S., Moioli, S., Stalder, C. K., Santinelli, L., Echsel, A., \& Schulze, C. (2019). Occupational therapy practice in mainstream schools: Results from an online survey in Switzerland. Occupational Therapy International, 2019. doi:

$10.1155 / 2019 / 3647397$

Koppleman, J. (2004). Children with mental disorders: Making sense of their needs and systems that help them. NHPF Issue Brief. No. 799. Washington, DC: National Health Policy Forum, George Washington University.

Lutz, A., Slagter, H. A., Dunne, J. D., \& Davidson, R. J. (2008). Attention regulation and monitoring in meditation. Trends in Cognitive Sciences, 12(4), 163-169.

Lynagh, M., Gilligan, C., \& Handley, T. (2010). Teaching about, and dealing with, sensitive issues in schools: How confident are pre-service teachers? Asia-Pacific Journal of Health, Sport and Physical Education, 1(3-4), 5-11.

McGonigal, K. (2013). How to make stress your friend [YouTube video]. Retrieved from https://www.youtube.com/watch?v=RcGyVTAoXEU\&list=PLbiVpU59JkVZeQ PQ1u5mS8U1c0V7J5OJU\&index=2

Metz, S. M., Frank, J. L., Reibel, D., Cantrell, T., Sanders, R., \& Broderick, P. C. (2013). The effectiveness of the learning to BREATHE program on adolescent emotion regulation. Research in Human Development, 10(3), 252-272.

MentalHealth.gov. (2017). What is mental health? Retrieved from https://www.mentalhealth.go/basics/what-is-mental-health Mindful Schools. (2019). Retrieved from https://www.mindfulschools.org/resources/exploremindful-resources/\#guided-practices 
Mental Health America. (2020). Mental health treatments. Retrieved from https://www.mhanational.org/mental-health-treatments

National Alliance on Mental Illness. (2019). Mental health by the numbers. Retrieved from https://www.nami.org/Learn-More/Mental-Health-By-the-Numbers

National Alliance on Mental Illness. (2019). Mental health in schools. Retrieved from https://www.nami.org/Learn-More/Public-Policy/Mental-Health-in-Schools

National Association of School Psychologists. (2019). School based mental health services: Improving student learning and well-being. Retrieved from https://www.nasponline.org/resources-and-publications/resources-and-podcasts/mentalhealth/school-psychology-and-mental-health/school-based-mental-health-services

National Geographic. (2015). Stress, portrait of a killer with Robert Sapolsk [YouTube video]. Retrieved from https://www.youtube.com/watch?v=a58RrLUs4YE\&list=PLbiVpU59JkVZeQ PQ1u5 mS8U1c0V7J5OJU\&index $=1$

Neuroscientifically Challenged. (2014, June 24). Know your brain: Amygdala [Blog post]. Retrieved from https://www.neuroscientificallychallenged.com/blog/know-your-brainamygdala

Office of Migrant Education. (2001). Comprehensive needs assessment [PDF]. Retrieved from https://www2.ed.gov/admins/lead/account/compneedsassessment.pdf

Palousemindfulness.com. (n.d.). Mindfulness based stress reduction: An introduction. Retrieved from https://palousemindfulness.com/MBSR/week0.html 
Poulin, M. J., Brown, S. L., Dillard, A. J., \& Smith, D. M. (2013). Giving to others and the association between stress and mortality. American Journal of Public Health, 103(9), 1649-1655. doi: 10.2105/AJPH.2012.300876

Practicalnursing.org. (2019). The importance of holistic nursing care: How to completely care for your patients. Retrieved from https://www.practicalnursing.org/importance-holisticnursing-care-how-completely-care-patients

Roeser, R., Schonert-Reichl, K. A., Jha, A., Cullen, M., Wallace, L., Wilensky, R., ... Harrison, J. (2013). Mindfulness training and reductions in teacher stress and burnout: Results from two randomized, waitlist-control field trials. Journal of Educational Psychology, 105(3), 787-804.

Rothi, D. M., Leavey, G., \& Best, R. (2008). On the front-line: Teachers as active observers of pupils' mental health. Teaching and Teacher Education: An International Journal of Research and Studies, 24(5), 1217-1231.

Sanchez, A. L., Comacchio, D., Poznanski, B., Golik, A. M., Chou, T., \& Comer, J. S. (2018). The effectiveness of school-based mental health services for elementary-aged children: A meta-analysis. Journal of the American Academy of Child \& Adolescent Psychiatry, $57(3), 153-165$.

Schall, J., LeBaron Wallace, T., \& Chhuon, V. (2016). "Fitting in” in high school: How adolescent belonging is influenced by locus of control beliefs. International Journal of Adolescence and Youth, 21(4), 462-475. http://dx.doi.org/10.1080/02673843.2013.866148

Schonert-Reichl, K. A., Oberle, E., Lawlor, M. S., Abbott, D., Thomson, K., Oberlander, T. F., \& Diamond, A. (2015). Enhancing cognitive and social-emotional development through 
a simple-to-administer mindfulness-based school program for elementary school children: A randomized controlled trial. Developmental Psychology, 51(1), 52-66.

Sedlmeier, P., Eberth, J., Schwarz, M., Zimmermann, D., Haarig, F., Jaeger, S., \& Kunze, S. (2012). The psychological effects of meditation: A meta-analysis. Psychological Bulletin, 138(6), 1139.

Sibinga, E.M., Webb., L, Ghazarian, S.R., \& Ellen, J.M. (2016). School-based mindfulness instruction: A RCT. Pediatrics, 137(1), e20152532.

http://dx.doi.org/10.1542/peds.2015-2532

Stosny, S. (2011). Self-regulation. Retrieved from https://www.psychologytoday.com/us/blog/anger-in-the-ageentitlement/201110/self-regulation

Terada, Y. (2017). Mindfulness is all the rage - but does it work? Retrieved from https://www.edutopia.org/article/mindfulness-all-the-rage-does-it-work-youki-terada US Department of Health and Human Services (HHS). (2018).

Adolescent mental health basics. Retrieved from https://www.hhs.gov/ash/oah/adolescent-development/mental-health/adolescent-mentalhealth-basics/index.html

Walter, H. J., Gouze, K., \& Lim, K. G. (2006). Teachers' beliefs about mental health needs in inner city elementary schools. Journal of the American Academy of Child and Adolescent Psychiatry, 45(1), 61-68.

Whiting, C. C. (2018). Trauma and the role of the school-based occupational therapist. Journal of Occupational Therapy, Schools, \& Early Intervention, 11(3), 291-301. DOI: $10.1080 / 19411243.2018 .1438327$ 
World Federation of Occupational Therapists. (2016). Position statement: Occupational therapy services in school-based practice for children and youth [PDF file]. Retrieved from https://www.apeto.com/assets/servicios-de-to-en-prácticas-basadas-en-los-colegiosniños-y-adolescentes--inglés.pdf

Youth.gov. (n.d.). Prevalence of use, abuse, and dependence. Retrieved from https://youth.gov/youth-topics/substance-abuse/prevalence-substance-use-abuse- anddependence

Zenner, C., Herrnleben-Kurz, S., \& Walach, H. (2014). Mindfulness-based interventions in schools- a systematic review and meta-analysis. Frontiers in Psychology. Retrieved from https://www.frontiersin.org/articles/10.3389/fpsyg.2014.00603/full 
Appendix A

\section{Week One Journal}

Mindfulness activity:

Grade:

1. Summarize what you saw happen in your classroom this week (Behavior of students, peer interactions, reactions to activities, atmosphere of classroom, etc)?

2. What would you rate the effectiveness of this activity?

$\begin{array}{llllllllll}1 & 2 & 3 & 4 & 5 & 6 & 7 & 8 & 9 & 10\end{array}$

3. What would you change about this activity to make it better? 